\title{
Effect of Spraying Calcium Fertilizer on the Fruit Quality of 'Ruby Seedless' grape
}

\author{
Yan Huang ${ }^{1 \mathrm{a}}$, Xiaoli Ma ${ }^{2 \mathrm{~b}}$, Wenjie $\mathrm{HU}^{1 \mathrm{c}}$ and Jin Wang ${ }^{1 \mathrm{~d} *}$ \\ ${ }^{1}$ Institute of Pomology and Olericulture, Sichuan Agricultural University, Chengdu, Sichuan, China \\ ${ }^{2}$ Chongqing three gorges academy of agricultural sciences, Wanzhou, Chongqing, China \\ a275477909@qq.com, b545298645@qq.com, c790307626@qq.com, d251040278@qq.com \\ ${ }^{*}$ Corresponding author. Yan Huang and Xiaoli Ma contributed equally to this work.
}

\begin{abstract}
Keywords: Grapes; Color-changed period; Calcium nitrate solution; Fruit quality
Abstract: Three-year-old 'ruby seedless' grapes were used for trial material to study the effects of spraying with the different concentrations of calcium fertilizer on grape fruit external quality and intrinsic quality. Fruits were sprayed $0.1 \%, 0.2 \%, 0.3 \%$ Calcium nitrate solution during the fruit color-changed period, and fruits were sprayed clear water for the check. The results showed that the different concentrations of calcium fertilizer improved the appearance quality and intrinsic quality of the 'ruby seedless' grape fruit. Compared with the control, spraying $0.3 \%$ calcium nitrate solution had the most significant effect. The fruit weight of the grape increased by $23.4 \%$, the fruit firmness increased by $83.6 \%$, the content of the titratable acid decreased by $24.7 \%$, the content of soluble solids increased by $16.33 \%$, the content of soluble sugar increased by $27.53 \%$, and the content of Vc increased by $19.0 \%$. The results of this experiment provided some guidance for supplementing calcium and improving fruit quality in grape production.
\end{abstract}

\section{Introduction}

Grape is a kind of calcium-loving fruit, the demand for calcium is much higher than apple, pear, citrus and so on. Calcium is a necessary large number of nutrient elements for plant growth and development and plays an important role in many physiological processes of plants [1]. $\mathrm{Ca}^{2+}$ not only can maintain the cell wall structure [2], make the fruit keep firmness, reduce decay of fruit postharvest storage transportation condition, and can resist some of the common physiological diseases of fruit tree [3-6] in some ways. On the other hand, $\mathrm{Ca}^{2+}$ also can strengthen to translocate organic matter. Studies have shown that when calcium is deficient, the amount of sugar accumulation of photosynthesis in plants is significantly reduced, compared with the condition of sufficient calcium, enhancing rapidly sugar output after increasing calcium [7] in a certain range.

In the modern agricultural production, because calcium plays an important role of fruit in the growth and development, the influence of exogenous calcium element in the production of the fruit yield and quality has obtained more and more attention, especially in the late stage of fruit development, the calcium content in fruits often can determine the quality and storability of the fruit. According to the research of the Li bingzhi, Su mingshen [8-9], the results showed that during the period of fruit growth, exogenous calcium fertilizer could significantly increase the content of soluble sugar and Vc content in fruit, at the same time could increase the firmness and gloss, significantly improve the comprehensive quality of the fruit. This experiment is to explore its influence on 'ruby seedless' grape fruit quality by spraying different concentration of calcium nitrate solution during the fruit color-changed period, in order to provide certain reference for grape production practice.

\section{Materials and Methods}

Materials. Three-year-old 'ruby seedless' grapes were used in this study. Grapes grown robustly, having the same management and without plant diseases and insect pests. The experimental site is the vineyard of modern research and development base of Sichuan Agricultural University. The garden adopts double membrane coverage, Y-shaped horizontal scaffolds and the facilities of 
prevent rainning cultivated. The row spacing is $1.5 \mathrm{~m} \times 3.0 \mathrm{~m}$ and 150 acres are planted.

Experimental Design. This experiment had three different concentrations of calcium fertilizer, and the concentration gradient was set as $0.1 \%, 0.2 \%$ and $0.3 \%$ respectively. Spraying water was set as a control (CK).Calcium nitrate was sprayed twice. The spraying time was during the fruit color-changed period (45 days and 55 days after flowering).A total of three treatments and one control were set up in the experiment, and a random group was arranged. Nine grapes were set for each treatment. Each treatment is sampled and brought back to the laboratory for measurement of relevant indicators when the fruit is ripe. In July 2017, after the fruits matured, 10 ears and 45 fruits were randomly selected from each treatment, and single panicle weight and single grain weight (accurate to $0.01 \mathrm{~g}$ ) were weighed with an electronic balance. The transverse and longitudinal diameters of the fruit were measured with a digital caliper and the fruit shape index was calculated. The hardness of the pulp was measured with a GY-1 type duromter. The content of soluble solids in the fruit was determined using a PAL-1 digital quantifier. The titratable acid content in the fruit was determined using the $\mathrm{NaOH}$ method [10]. The total sugar content was determined by anthrone colorimetry [11]. The VC content in fruits was determined using the 2, 6-dichlorophenol indophenol method [12].

Statistical Analyses. Data were analyzed using Excel 2010 and SPSS 13.0 statistical software (IBM, Chicago, IL, USA).

\section{Results and Discussion}

Effects of different concentration of calcium nitrate solution on external quality of 'ruby seedless' grape. Compared with the control, spraying $0.1 \%$ Calcium nitrate solution had no significant effects on weight of 'ruby seedless' grape. Three different treatments had no significant effects on vertical diameter and transverse diameter (Table 1). All treatments increased the fruit firmness of 'ruby seedless' grape. It increased by $83.6 \%, 63.0 \%, 57.5 \%$ respectively. The result showed that the application of calcium fertilizer had a good effect on the increase of fruit firmness.

Table 1 Effects of different concentration of calcium nitrate solution on external quality of 'ruby seedless' grape

\begin{tabular}{|c|c|c|c|c|c|}
\hline $\begin{array}{c}\text { Calcium fertilizer } \\
\text { concentrations } \\
(\%)\end{array}$ & $\begin{array}{c}\text { Fruit weight } \\
(\mathrm{g})\end{array}$ & $\begin{array}{c}\text { Vertical } \\
\text { diameter } \\
(\mathrm{cm})\end{array}$ & $\begin{array}{c}\text { Transverse } \\
\text { diameter } \\
(\mathrm{cm})\end{array}$ & $\begin{array}{c}\text { Fruit shape } \\
\text { index }\end{array}$ & $\begin{array}{c}\text { Fruit } \\
\text { firmness } \\
\left(\mathrm{kg} \cdot \mathrm{cm}^{-2}\right)\end{array}$ \\
\hline 0 & $5.400 \pm 0.211 \mathrm{~b}$ & $2.283 \pm 0.067 \mathrm{a}$ & $2.035 \pm 0.087 \mathrm{ab}$ & 1.120 & $0.73 \pm 0.099 \mathrm{~b}$ \\
\hline 0.1 & $5.709 \pm 0.188 \mathrm{~b}$ & $2.171 \pm 0.160 \mathrm{a}$ & $1.976 \pm 0.111 \mathrm{~b}$ & 1.099 & $1.15 \pm 0.329 \mathrm{a}$ \\
\hline 0.2 & $6.424 \pm 0.179 \mathrm{a}$ & $2.240 \pm 0.140 \mathrm{a}$ & $2.021 \pm 0.096 \mathrm{ab}$ & 1.108 & $1.19 \pm 0.245 \mathrm{a}$ \\
\hline 0.3 & $6.662 \pm 0.176 \mathrm{a}$ & $2.358 \pm 0.117 \mathrm{a}$ & $2.051 \pm 0.106 \mathrm{a}$ & 1.150 & $1.34 \pm 0.214 \mathrm{a}$ \\
\hline
\end{tabular}

Note: Different lowercase letters marked with the same column data indicate a significant difference $(\mathrm{P}<0.05)$, the same as the following table.

Effects of different concentration of calcium nitrate solution on intrinsic quality of 'ruby seedless' grape. Compared with the control, three treatments all increased TSS of 'ruby seedless' grape (Table 2).TSS increased by $9.80 \%, 11.30 \%, 16.33 \%$ respectively. This result showed that spraying calcium fertilizer could improve TSS of 'ruby seedless' grape and improve the fruit quality. Moreover all treatments decreased the content of titratable acid of 'ruby seedless' grape. The titratable acid content decreased by $18.39 \%, 21.26 \%, 24.7 \%$ respectively. Compared with the control, all treatments had significant effects on increasing soluble sugar content of 'ruby seedless' grape. The content of soluble sugar of $0.2 \%$ calcium nitrate solution increased by $40.05 \%$ mostly. 
Spraying $0.1 \%$ calcium nitrate solution had no significant effects on the Vitamin $\mathrm{C}$ content, other treatments could increase Vc content of 'ruby seedless' grape. Thus, spraying $0.3 \%$ calcium nitrate solution could improve intrinsic quality of 'ruby seedless' grape.

Table 2 Effects of different concentration of calcium nitrate solution on intrinsic quality of 'ruby seedless' grape

\begin{tabular}{|c|c|c|c|c|c|}
\hline $\begin{array}{c}\text { Calcium fertilizer } \\
\text { concentrations } \\
(\%)\end{array}$ & TSS $(\%)$ & $\begin{array}{c}\text { Titratable } \\
\text { acid content } \\
(\%)\end{array}$ & $\begin{array}{c}\text { Tss-acid } \\
\text { ratio }\end{array}$ & $\begin{array}{l}\text { Soluble sugar } \\
\text { content }(\%)\end{array}$ & $\begin{array}{c}\text { Vitamin C } \\
\text { content } \\
\left(\mathrm{mg} \cdot 100 \mathrm{~mL}^{-1}\right)\end{array}$ \\
\hline 0 & $17.26 \pm 0.52 \mathrm{c}$ & $0.522 \pm 0.018 \mathrm{a}$ & 33.06 & $11.659 \pm 0.008 \mathrm{~d}$ & $5.37 \pm 0.043 \mathrm{c}$ \\
\hline 0.1 & $18.95 \pm 0.899 \mathrm{~b}$ & $0.426 \pm 0.024 \mathrm{~b}$ & 44.48 & $15.797 \pm 0.033 \mathrm{~b}$ & $5.47 \pm 0.036 \mathrm{c}$ \\
\hline 0.2 & $19.21 \pm 0.485 \mathrm{~b}$ & $0.411 \pm 0.003 \mathrm{~b}$ & 46.74 & $16.328 \pm 0.074 \mathrm{a}$ & $5.84 \pm 0.018 \mathrm{~b}$ \\
\hline 0.3 & $20.08 \pm 0.652 \mathrm{a}$ & $0.393 \pm 0.001 \mathrm{~b}$ & 51.09 & $14.870 \pm 0.016 \mathrm{c}$ & $6.39 \pm 0.019 \mathrm{a}$ \\
\hline
\end{tabular}

\section{Discussion}

In this study, the result showed that $0.3 \%$ calcium nitrate solution could increase fruit weight and fruit firmness of 'ruby seedless' grape, thereby increasing the fruit resistance of storage and transport, reducing the fruit dehiscent rate, avoiding mechanical damage in the process of storage and transportation, and could prolong the goods shelf life of 'ruby seedless' grape. This result was consistent with the research of Che yuhong [13].At the same time, spraying $0.3 \%$ calcium nitrate solution also increased the intrinsic quality of 'ruby seedless' grape fruit. It not only increased soluble solid content of 'ruby seedless' grape, but also decreased fruit titratable acid content, indicating that $0.3 \%$ calcium nitrate improved the taste of grape fruits. The vitamin $\mathrm{C}$ content of the fruit also increased. Vitamin $\mathrm{C}$ content was an important criterion to evaluate the nutritive value of fruit, which indicated that the fruits treated with calcium nitrate were more nutritious and healthy than those of the control group. The effect of calcium on the inner quality of fruit was consistent with the conclusions of Xu xinglin [14], Su xuede [15] and Liu xinming [16].

\section{Conclusions}

The results showed that spraying $0.3 \%$ of the calcium nitrate solution during the fruit color-changed period could increase fruit weight and fruit firmness of 'ruby seedless' grape, thus improving appearance quality of 'ruby seedless' grape. On the other hand, spraying $0.3 \%$ of the calcium nitrate solution during the fruit color-changed period increased TSS、Soluble sugar content and Vitamin C content of 'ruby seedless' grape, and decreased titratable acid content of 'ruby seedless' grape. It had significant effects on improving intrinsic quality of 'ruby seedless' grape. The results had certain reference value to provide exogenous calcium and improve the quality of grape fruit.

\section{Acknowledgements}

This work was financially supported by the Viticulture Technology Research Position of the Sichuan Fruit Innovation Team of the National Modern Agricultural Industry Technology System.

\section{References}

[1] J.F. Guan, MaxSaure: Science press, 2005

[2] X.M. Huang, H.B. Huang, H.C. Wang:Scientia Horticulturae Vol. 3 (2005), p. 249

[3] C. Alcaraz-Lopez, M. Botia, C.F. Alcaraz: Journal of Plant Physiology Vol.160(2003), p. 1441

[4] Y.H. Che, B.Z. Li, Y.G. Wang: Journal of northwestern botany Vol. 25 (2005),p. 803 
[5] C. Chervin, D. Lavigne, P. Westercamp: Postharvest Biology \& Technology Vol. 54(2009), p. 115

[6] A. Ciccarese, A.M. Stellacci, G. Gentilesco: Postharvest Biology \& Technology Vol. 75(2013), p. 135

[7] C.W. Sun, Z. Chen,J.G. Wei: Hebei forestry technology Vol. 4(2015),p. 128

[8] B.Z. Li, J. Liang, L.S. Zhang: Journal of northwest forestry college Vol. 16(2001), p. 26

[9] M.S. Su, Z.W. Ye, S.Y. Li: Fruit trees of southern China Vol. 36(2007), p. 77

[10] Z.A. Zhang, M.S. Zhang, R. Wei: Plant Physiology experiment Guide (China Agricultural Science and Technology Press, Beijing, China 2004)

[11] H.S. Li: Physiological and Biochemical experiment Principles and Techniques (Higher Education Press, Beijing, China 2000)

[12] Q. Zou: Plant Physiology experiment Guide (China Agriculture University Press, Beijing, China 2004)

[13] Y.H. Che: Xinjiang agricultural science Vol. 48(2011), p.744

[14] X.L. Xu, Z.J. Wang, Y.H. Guo: Chinese and foreign grape and wine Vol. 4 (2002), p. 40

[15] X.D. Su, J.S. Yang:Journal of gansu agricultural university Vol. 44(2009), p.73

[16] X.M Liu, T. Chen, Y. Lie: The influence of fujian agricultural journal Vol. 12(2013), p. 1252 